\title{
Diagnostic and Clinical Utility of Immunohistochemistry in Papillary Thyroid Carcinoma
}

\author{
Norhan M. A. Omar Kolaib*, Bassma M. Elsabaa, Amel A. Shaban \\ Pathology Dept. Faculty of Medicine, Egypt
}

\begin{abstract}
*Corresponding Author: Norhan M. A. Omar Kolaib, Pathology Dept.Faculty of Medicine, Egypt,
\end{abstract} Email: nourhankolaib88@gmail.com

\begin{abstract}
Background: Diagnosing papillary thyroid carcinoma (PTC), especially follicular variant of PTC and predicting it's malignant behaviour have been the two most contentious areas in thyroid pathology.
\end{abstract}

Aim of the work: was to investigate the immunohistochemical expression of $\mathrm{N}$-Cadherin in well differentiated and follicular variant of PTC and is correlated with different clinicopathological variables.

Patients and methods: In the present study, $N$-Cadherin was evaluated in 53 cases and 10 cases of colloid nodular goiter(C.N.G).

Results: The expression rate of $N$-cadherin was $81.4 \%$ in PTC. The expression rate of $N$-cadherin in PTC with metastatic lymph nodes was $100 \%$, while in PTC without lymph node metastasis (L.N.M), the expression rate of $N$-cadherin was $72 \%$ respectively. The expression rate of $N$-cadherin in PTC with extra thyroidal extension (ETE) was $100 \%$, while in PTC without ETE, the expression rate was $76.7 \%$.

Conclusion: The present study showed that $N$-Cadherin immunohistochemistry can potentially be used for differential diagnosis between PTC and C.N.G and their expression is significantly associated with extrathyroidal extension and lymph node metastasis.

\section{INTRODUCTION}

Thyroid cancer is one of the most common endocrine malignancies. Papillary thyroid carcinoma (PTC) is one of the most common subtypes of thyroid cancer with excellent prognosis as it is one of the most curable cancers and has a relatively favourable longterm survival after appropriate treatment. It is characterized by a slowly progressive course and a 10-year survival rate approximately $90 \% .^{(1)}$

The pathological diagnosis of PTC in both cytological and histological specimens is based upon the demonstration of typical nuclear morphology ${ }^{(2)}$. Using morphological criteria, most PTCs can be diagnosed with ease, except cases in which there is a paucity of diagnostic nuclear features ${ }^{(2,3)}$. Immunohistochemical markers can help distinguish PTCs from benign thyroid lesions. ${ }^{(4,5)}$

Cadherins (named for "calcium-dependent adhesion") are a class of type1 transmembrane proteins. They are synthesized as polypeptides and undergo many post-translational modifications to become the proteins which mediate cell-cell adhesion(through adherent junctions) and recognition. ${ }^{(6)}$

These polypeptides are approximately $720-750$ amino acids long. Cadherins have a large extracellular domain for intercellular homotypic connections and a cytoplasmic domain which interacts with cytoplasmic proteins called catenins ( $\alpha-, \beta$ - and $\gamma$-catenin) that link to the actin-based cytoskeleton. ${ }^{(7,}{ }^{8)}$ Cadherin-catenin complexes are critical for signal transduction and various cellular functions. ${ }^{(7)}$

$\mathrm{N}$-cadherin (neuralcadherin) is a kind of adhesion molecule which is often over expressed in many types of cancers, such as breast cancer and colorectal cancer, and is an inducer of epithelial-to-mesenchymal transition (EMT) which is play an important role during the early stage of invasion and metastasis of cancer. $^{(9,10)}$

The prognosis of PTC depends on several wellestablished clinicopathological criteria, 
including age $\geq 45$, histologic subtype, increasing tumor size, lympho-vascular space invasion (LVSI), ETE, and the presence LNM or distant metastasis $^{(11)}$.

Aim of the Present Work was to: Study the expression of $\mathrm{N}$-cadherin in cases of papillary thyroid carcinoma (PTC) and correlate the expression profile with the different clinicopathalogical variables.

\section{MATERIAL}

The current study entailed retrospective analysis of 53 thyroid ectomy specimens (10 benign nodular goiters and 43 conventional PTC) diagnosed in Alexandria Main University Hospital. Formalin-fixed paraffin-embedded blocks was obtained from the archive of material available in the Pathology Department, Faculty of Medicine, Alexandria University from year 2010 to the year 2015 .

\section{METHODS}

In the present study, the work protocol entailed the following:

\subsection{Clinical Data}

Clinical data including the patients' age, gender, clinical presentation, and type of operation (total, subtotal or hemithyroidectomy) were obtained by reviewing the pathology request forms and patients' clinical sheets.

\subsection{Pathological Examination}

\section{a. Gross Examination}

The macroscopic features of the specimens were obtained from the pathology reports archived at the pathology department, Faculty of Medicine, University of Alexandria.

\section{b. Histopathologic Examination}

Formalin-fixed paraffin-embedded tissue blocks were cut into five micron-thick sections, stained with hematoxylin and eosin (H\&E) stain and reviewed. Tumor typing was done according to the WHO classification of thyroid tumors $^{(12)}$.

\section{c. Immunohistochemistry}

Immunohistochemical staining was conducted by employing the streptavidin -biotinperoxidase complex method.

Primary antibody: N-cadherin: a mouse monoclonal antibody ( clone D-4) against amino acids 450-512 within the extracellular domain of $\mathrm{N}$-cadherin of human origin purchased from SantaCruz Biotechnology, USA (Catalogue ARC Journal of Cancer Science number sc-8424) With dilution range 1:501:500.

\section{Immunohistochemical Staining Protocol included the following steps:}

1. Four microns thick sections were deparaffinized in xylene and rehydrated in a graded alcohol series (100\% to $70 \%)$.

2. Slides were then washed 2 times in phosphate-buffered saline (PBS) each for 5 minutes.

3. Slides were incubated in Hydrogen Peroxide Block for 10-15 minutes, to block endogenous peroxidase activity in order to reduce nonspecific background staining.

4. Then the slides were washed 4 times in PBS each for 5 minutes.

5. Slides were then immersed in sodium citrate buffer $(0.01 \mathrm{M}$ Na-citrate monohydrate, $\mathrm{pH}$ 6.0 ) in plastic Coplin jars and incubated in a microwave oven for $5 \mathrm{~min}$ twice, then allowed to cool down to room temperature.

6. Sections were then washed by PBS 4 times each for $5 \mathrm{~min}$.

7. Slides were incubated with Ultra V Block for $5 \mathrm{~min}$ at room temperature to block nonspecific background staining.

8. Primary antibody was then applied (diluted 1:100 with PBS) and incubated overnight at $40 \mathrm{C}$ in a humidified chamber.

9. Sections were washed 4 times in PBS each for $5 \mathrm{~min}$.

10. The slides were incubated with Biotinylated Goat Antipolyvalent for $10 \mathrm{~min}$ then washed 4 times each for $5 \mathrm{~min}$.

11. Then the sections were incubated with streptavidin peroxidase for $10 \mathrm{~min}$.

12. The slides were washed 4 times each for 5 min.

13. A mixture of one drop DAB chromogen and $2 \mathrm{ml}$ of DAB substrate was applied to slides for $15 \mathrm{~min}$.

14. The slides were then washed 4 times in tap water.

15. Slides were counterstained with Meyer hematoxylin and covered by a cover slip and microscopically examined by a light microscope. 
Evaluation of N-Cadherin immunostaining:

All tissue sections were evaluated considering membranous and cytoplasmic N-cadherin staining and using an immunoreactive staining score (IRS). ${ }^{(13)}$

a) The intensity of staining was evaluated on a graded scale ${ }^{(14,15)}: 0=$ (no color), $1=$ weak (faint yellow), 2= Intermediate (yellow), 3= strong (brown yellow).

b) The extent (percentage) of positive cells: This was scored $^{(14)}$ using a $0-4$ scoring system: Score $0=0 \%$ positive cells, Score $1=$ less than $10 \%$ positive cells, Score $2=$ $10-50 \%$ positive cells, Score $3=51-80 \%$ positive cells and Score $4=>80 \%$ positive cells.

For the final IRS, the scores of intensity and staining were multiplied ${ }^{(14)}$

Negative (omitted antibody) and positive (formalin fixed, paraffin-embedded human liver tissue) controls were included in all runs.

\section{Statistical Analysis of the Data}

Data were fed to the computer and analysed using IBM SPSS software package version 20.0. Qualitative data were described using number and percent. Quantitative data were described using range (minimum and maximum), mean, standard deviation and median. Significance of the obtained results was judged at the $5 \%$ level.

\section{The Used Tests were:}

\section{- Chi-Square Test}

For categorical variables, to compare between different groups

\section{- Fisher's Exact or Monte Carlo Correction}

Correction for chi-square when more than $20 \%$ of the cells have expected count less than 5

\section{RESULTS}

\section{Distribution of the Studied Patients Regarding Clinical Data:}

Regarding tumor size, 11 cases $(25.6 \%)$ were $<2,10$ case $(23.2 \%)$ were $>2-\leq 4$ and 22 cases $(51.1 \%)$ were $>4$.

Regarding focality of the tumor, 25 cases $(58.1 \%)$ were multifocal, 18 cases $(41.9 \%)$ were unifocal.
Concerning Lymphovascular space invasion, it was present in 30 cases $(69.7 \%)$.

As regards lymph node metastasis, it was positive in 18 cases $(41.8 \%)$.

Regarding extrathyroidayextension, it was found in 13 cases $(30.2 \%)$

\section{Histopathological Examination:}

The prepared H\&E stained sections from each case were carefully reviewed and the studied sections were classified histopathologically into Table1.

\section{I-Neoplastic group:}

This category included 43 cases

1. Conventional PTC: This group included 25 cases $(58.1 \%)$

2. Non-encapsulated FVPTC: This group included 11 cases $(25.6 \%)$.

3. Encapsulated FVPTC: This group included 5 cases $(11.6 \%)$

4. Columnar cell variant PTC: This group included 2 cases $(4.7 \%)$

\section{II-Control Group:}

This category included 10 cases of colloid nodular goiter

Table1. Distribution of the studied Cases regarding histopathological variant of PTC.

\begin{tabular}{|l|l|l|}
\hline & \multicolumn{2}{|c|}{ Cases } \\
\hline $\begin{array}{l}\text { Histopathologic variant of } \\
\text { PTC }\end{array}$ & Number & Percent \\
\hline WDPTC & 25 & 58.1 \\
\hline Non-encaps FVPTC & 11 & 25.6 \\
\hline Encaps FVPTC & 5 & 11.6 \\
\hline Columnar & 2 & 4.7 \\
\hline Total & 43 & 100.0 \\
\hline
\end{tabular}

The Correlation between the Expression of NCadherin, and Clinicopathological Indicators of PTC Table 2

The expression of $\mathrm{N}$-cadherin was not statistically significant with the gender, age of PTC patients, and the tumor size ( $p>0.05)$.

There was statistically significant relation between IRS of N-Cadherin and LVSI, L.N metastasis \& ETE. 
Table2. Relation between IRS of $N$-cadherin and different clinicopathological variables

\begin{tabular}{|l|l|l|l|}
\hline & $\begin{array}{l}\text { IRS of N- } \\
\text { cadherin }\end{array}$ & Test & p \\
\hline $\begin{array}{l}\text { Age group } \\
<45 \\
>45\end{array}$ & $\begin{array}{l}3.67 \pm 2.94 \\
5.69 \pm 4.24\end{array}$ & 1.68 & 0.072 \\
\hline $\begin{array}{l}\text { Sex } \\
\text { Male }\end{array}$ & $\begin{array}{l}4.60 \pm 2.988 \\
\text { Female }\end{array}$ & 0.129 & 0.921 \\
\hline $\begin{array}{l}\text { Tumor size } \\
\leq 2 \\
>2-\leq 4\end{array}$ & $2.55 \pm 2.07$ & 1.511 & 0.114 \\
$>4$ & $\begin{array}{l}4.60 \pm 3.44 \\
5.27 \pm 3.97\end{array}$ & & \\
\hline $\begin{array}{l}\text { Lymphovascular } \\
\text { invasion }\end{array}$ & & & \\
$\begin{array}{l}\text { Present } \\
\text { Absent }\end{array}$ & $5.63 \pm 3.48$ & 15.471 & p $<.001$ \\
\hline $\begin{array}{l}\text { Lymph } \\
\text { metastasis }\end{array}$ & $1.62 \pm 1.76$ & & \\
$\begin{array}{l}\text { Present } \\
\text { Absent }\end{array}$ & $7.06 \pm 2.69$ & 27.653 & $0.0001^{*}$ \\
\hline $\begin{array}{l}\text { Extrathyroidal } \\
\text { extension }\end{array}$ & $2.52 \pm 2.86$ & & \\
$\begin{array}{l}\text { Present } \\
\text { Absent }\end{array}$ & $7.92 \pm 2.63$ & 30.700 & $0.0001^{*}$ \\
\hline
\end{tabular}

Data was presented as Mean \pm S.D.

Relation between Malignant (PTC) Cases and Benign Cases (C.N.G) Regarding IRS of NCadherin Table3.

\begin{tabular}{|c|c|c|}
\hline $\begin{array}{l}\text { IRS of N- } \\
\text { Cadherin }\end{array}$ & PTC cases & $\begin{array}{l}\text { Control } \\
\text { group }(\mathrm{CN} . \mathrm{G})\end{array}$ \\
\hline Range & $0-12$ & $0-0$ \\
\hline Mean & 4.418 & 0.0 \\
\hline S.D. & 3.56 & 0.0 \\
\hline $\begin{array}{l}\text { t-test } \\
\mathrm{p}\end{array}$ & $\begin{array}{l}19.65 \\
0.0001 * * *\end{array}$ & \\
\hline
\end{tabular}

In the present study the median total score of Ncadherin immunopositivity among PTC cases $(M d n=4)$ was significantly higher than that among control group ( $M d n=0), \mathrm{P}=0.0001$

The diagnostic accuracy of $\mathrm{N}$-cadherin expression was further tested by ROC curve analysis in order to detect a cut-off point above which malignancy is predicted.

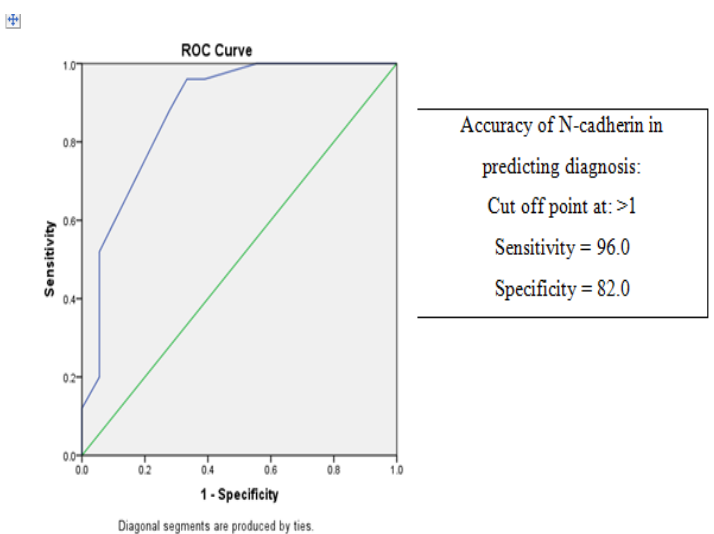

Figure1. ROC curve to determine the cut off value of $N$-cadherin sensitivity and specificity to detect the malignant cases.
The current study revealed that the cut off value of scoring $\mathrm{N}$-cadherin if more than 1 it was diagnosed as malignant by sensitivity $96.0 \%$ and specificity $82.0 \%$ (Figure 1 ).

\section{DISCUSSION}

The current retrospective study used immunohistochemical analysis of the expression of $\mathrm{N}$-cadherin in different histopathological variants of PTC and correlated the expression profile with the different clinicopathalogical features of the sampled tumors.

In the current study, The age of the patients ranged between 12 and 78 years with a mean of $42.31 \pm 16.05$ years and a median of 40.0 years and this was in agreement with Yang etal ${ }^{(9)}$ who stated that the age of patients is ranged from 15 to 70 years old and the median age is 40 years old. In the control group, the mean age was $40.1 \pm 15.6$ with a median of 38.0 years.

In the present study, we demonstrated that $\mathrm{N}$ cadherin, a key marker of EMT, was frequently over expressed in primary PTCs as compared to control subjects, it was found that all C.N.G cases were negatively expressed which are in keeping with Yang et al. ${ }^{(15)}$ and Da C et al ${ }^{(16)}$ who reported a negative expression in noncancerous thyroid tissues.

In the present study, there was no statistically significant correlation between patients' age, gender, tumor size and N-Cadherin expression $(\mathrm{p}>0.05)$ and this was in parallel to Yang et $a l^{(15)}$ who found that there was no statistically significant relation between patients' age, gender, tumor size and $\mathrm{N}$ - Cadherin expression.

The IRS of N-Cadherin was significantly higher in the group with nodal metastasis $(n=18)$ compared to the non-metastatic group $(n=25)$ $(p=0.0001)$. These results are in agreement with those of Yang et al. $^{(15)}$ that recorded a statistically significant higher $\mathrm{N}$-cadherin in patients with nodal metastasis. Therefore, we considered that expression of $\mathrm{N}$-cadherin is closely associated with PTC lymph node metastasis.

In the current study, the IRS of N-cadherin in group with ETE was significantly higher than the group with no ETE $(\mathrm{p}=0.0001)$.

Several previous studies are in general agreement with results of the present study as they revealed that $\mathrm{N}$-cadherin was exclusively or predominantly expressed in malignant tumors as urothelial tumors, pancreatic carcinoma and colorectal carcinoma compared to their benign counterparts or normal tissues. ${ }^{(17-19)}$ 
From the aforementioned results it could be suggested that immunostaining of $\mathrm{N}$-Cadherin may play an important role in the diagnosis and prediction of the biological behavior of different histopathological types of PTC. In addition it can potentially be used for differential diagnosis between PTC and MNG and for prediction of synchronous metastatic existence.

\section{REFRENCES}

[1] Jonklaas J, Sarlis NJ, Litofsky D, Ain KB, Bigos ST, Brierley JD, et al. Outcomes of patients with differentiated thyroid carcinoma following initial therapy. Thyroid. 2006;16(12):1229-42.

[2] Baloch ZW, LiVolsi VA. Pathologic diagnosis of papillary thyroid carcinoma: today and tomorrow. Expert review of molecular diagnostics. 2005; 5(4):573-84.

[3] Papale F, Cafiero G, Grimaldi A, Marino G, Rosso F, Mian C, et al. Galectin-3 expression in thyroid fine needle cytology (t-FNAC) uncertain cases: Validation of molecular markers and technology innovation. Journal of cellular physiology. 2013; 228(5):968-74.

[4] Weber T, Schilling T, Büchler MW. Thyroid carcinoma. Current opinion in oncology. 2006; 18(1):30-5.

[5] Saleh HA, Feng J, Tabassum F, Al-Zohaili O, Husain M, Giorgadze T. Differential expression of galectin-3, CK19, HBME1, and Ret oncoprotein in the diagnosis of thyroid neoplasms by fine needle aspiration biopsy. Cytojournal. 2009; 6(1):18.

[6] Harris TJ, Tepass U. Adherens junctions: from molecules to morphogenesis. Nature reviews Molecular cell biology. 2010;11(7): 502-14.

[7] Klezovitch O, Vasioukhin V. Cadherin signaling: keeping cells in touch. F1000Research. 2015; 4(F1000 Faculty Rev).

[8] Perez-Moreno M, Fuchs E. Catenins: keeping cells from getting their signals crossed. Developmental cell. 2006; 11(5):601-12.

[9] Hazan RB, Phillips GR, Qiao RF, Norton L, Aaronson SA. Exogenous expression of $\mathrm{N}$ cadherin in breast cancer cells induces cell migration, invasion, and metastasis. The Journal of cell biology. 2000; 148(4):779-90.

[10] ElMoneim HMA, Zaghloul NM. Expression of E-cadherin, N-cadherin and snail and their correlation with clinicopathological variants: an immunohistochemical study of 132 invasive ductal breast carcinomas in Egypt. Clinics. 2011; 66(10):1765-71.

[11] Sipos J, Mazzaferri E. Thyroid cancer epidemiology and prognostic variables. Clinical oncology. 2010; 22(6):395-404.

[12] Hedinger C, Dillwyn Williams E, Sobin LH. The WHO histological classification of thyroid tumors: a commentary on the second edition. Cancer. 1989; 63(5):908-11.

[13] El-Foll H, El-Sebaey H, El-Kased A, Hendawy A, Kamel M. Pattern and Distribution of Lymph Node Metastases in Papillary Thyroid Cancer. J Clin Exp Pathol. 2015;5(204):21610681.

[14] Bremmer F, Hemmerlein B, Strauss A, Burfeind P, Thelen P, Radzun H-J, et al. Ncadherin expression in malignant germ cell tumours of the testis. BMC clinical pathology. 2012; 12(1):19.

[15] Yang X, Shi R, Zhang J. Co-expression and clinical utility of Snail and N-cadherin in papillary thyroid carcinoma. Tumor Biology. 2016;37(1):413-7.

[16] Da C, Wu K, Yue C, Bai P, Wang R, Wang G, et al. N-cadherin promotes thyroid tumorigenesis through modulating major signaling pathways. Oncotarget. 2017;8(5):8131.

[17] Zhuo H, Jiang K, Dong L, Zhu Y, Lü L, Lü Y, et al. Overexpression of $\mathrm{N}$-cadherin is correlated with metastasis and worse survival in colorectal cancer patients. Chinese Science Bulletin. 2013; 58(28-29):3529-34.

[18] Nakajima S, Doi R, Toyoda E, Tsuji S, Wada $\mathrm{M}$, Koizumi $\mathrm{M}$, et al. N-cadherin expression and epithelial-mesenchymal transition in pancreatic carcinoma. Clinical Cancer Research. 2004; 10(12):4125-33.

[19] Lascombe I, Clairotte A, Fauconnet S, Bernardini S, Wallerand H, Kantelip B, et al. $\mathrm{N}$-cadherin as a novel prognostic marker of progression in superficial urothelial tumors. Clinical Cancer Research. 2006; 12(9):2780-7.

Citation: Norhan M. A. Omar Kolaib, Bassma M. Elsabaa, Amel A. Shaban. Diagnostic and Clinical Utility of Immunohistochemistry in Papillary Thyroid Carcinoma. ARC Journal of Cancer Science 2017; 3(2):8-12. DOI: http://dx.doi.org/10.20431/2455-6009.0302002

Copyright: (C) 2017 Authors. This is an open-access article distributed under the terms of the Creative Commons Attribution License, which permits unrestricted use, distribution, and reproduction in any medium, provided the original author and source are credited. 